\title{
Cross-linked hyaluronic acid gel occlusive device for the treatment of dry eye syndrome
}

This article was published in the following Dove Press journal: Clinical Ophthalmology

\author{
John P Fezza \\ Center for Sight, Sarasota, FL, USA
}

Correspondence: John P Fezza

Center for Sight, 260I South Tamiami

Trail, Sarasota, FL 34239, USA

Tel + I 94I 9252020

Fax + I 94I 3302200

Email jfezza@centerforsight.net
Purpose: A new cross-linked hyaluronic acid (xlHA) gel occlusive device was assessed for safety and efficacy in the treatment of dry eyes.

Methods: This was an institutional review board-approved, single-site, open-label, prospective study to assess the efficacy and safety of placing the xlHA gel in the lower canaliculus. Seventyfour participants aged 25-95 years with dry eyes, who failed treatment with artificial tears, were included. Patients were assessed with corneal slit lamp examination with fluorescein staining and with Schirmer's test, breakup time (TBUT), and tear meniscus height (TMH) at baseline, 1 month, and 3 months. Patients were followed at 6 months with a telephone questionnaire. The procedure entailed inserting $\sim 0.2 \mathrm{~mL}$ of xlHA gel into each lower lid canaliculus with a syringe and lacrimal irrigator. Patients were followed for adverse events.

Results: Sixty-three patients completed the study (48 females, 15 males), with an average age of 67 years. Slit lamp demonstrated improved corneal fluorescein staining. Schirmer's tests demonstrated an average increase over baseline of $3.67 \mathrm{~mm}$ after 3 months. TBUT improved $87 \%$ and TMH increased by $57 \%$ at 3 months over baseline. All objective measures were statically significant. There was one case of conjunctivitis that resolved and was felt to be an incidental viral infection.

Conclusion: The xlHA Occlusive Device offers a new, safe, and effective method to treat dry eyes. It appears to have efficacy for at least 3 months on clinical examination. The xlHA gel demonstrated a good tolerance and safety profile.

Keywords: dry eyes, punctal plugs, canalicular plugs, hyaluronic acid, gel occlusive device, cross-linked hyaluronic acid gel

\section{Introduction}

Dry eye syndrome (DES) is a common condition that affects millions of people worldwide. A proper tear film is essential for maintaining eye lubrication and clear vision. Symptoms of DES include foreign body sensation, burning, irritation, pain, and sensitivity to light.

The management of dry eyes is one of the most common disorders treated in an ophthalmic practice. Initial treatment of DES consists of medical therapy by replacing moisture with artificial tears and ointment. Punctal plugs are a common second-line treatment, and they function by blocking the outflow of tears from the eye. They have the advantage of using the patients' own tears to maintain the lubrication of the eye.

Plugs are made from a variety of materials, and there are several inherent problems with the current plug designs. Silicone plugs use a cap to hold the plug in place which sits above the lid margin, so that it does not slip into the deeper tear duct. The plug cap can rub on the surface of the eye causing ocular irritation. Sizing the correct plug can be challenging, and the plug can occasionally be lost if it is not properly fitted. 
Intracanalicular plugs have the benefit of being placed below the surface of the lid and therefore cannot rub on the eye, but they can act as a foreign body and cause canaliculitis.

The theory of blocking the outflow of tears is fundamentally sound, as it involves the use of patients' own tears to lubricate the eyes. The current plugs all have their unique drawbacks. An ideal canalicular occluder would be easy to place, block the outflow of tears effectively, be comfortable, biocompatible, long lasting, easily reversible, and have a low potential for infection. Cross-linked hyaluronic acid (xlHA) fits many of these desirable criteria.

HA is a natural, colorless, odorless mucopolysaccharide present in all mammals. Cross-linking free HA chains creates a more robust gel, which is more resistant to degradation. Synthetically xlHA is sufficiently soft to conform to the delicate inner walls of the canaliculus and theoretically block the tear outflow. A canalicular filler made of xlHA may be suitable for retaining tears on the surface of the eyes and potentially add its own lubricating effects, without rubbing on the ocular surface. This study describes a proof-of-concept pilot clinical study using synthetic xlHA gel as a canalicular occlusive device for the treatment of DES.

\section{Methods}

Sarasota Memorial Hospital institutional review board approval was granted to place xlHA gel in the canaliculus and tear duct for the treatment of DES. A prospective, single-site, open-label study with two board-certified ophthalmologists was conducted. Written informed consent was obtained from all study participants. The study was conducted in accordance with the Declaration of Helsinki and was HIPAAcompliant with the protection of individually identifiable health information.

Seventy-four patients aged from 25 to 95 years with a history of dry eyes and evidence of DES upon ocular examination were candidates for participation in this study. All patients had failed initial artificial tear drop treatment. A dry eye questionnaire based on the Ocular Surface Disease Index (OSDI) was administered to assess individual subjective dry eye symptoms.

Each participant underwent an initial external ophthalmologic examination and was assessed clinically for dry eyes with various measures including slit lamp examination (SLE) with corneal assessment with fluorescein staining, Schirmer's test with anesthesia, tear breakup time (TBUT), and tear meniscus height (TMH) at the initial visit, 1 month, and 3 months. A condensed exit questionnaire was conducted by phone at 6 months, and the responses were analyzed.

All patients underwent lacrimal irrigation at the initial visit to ensure a patent tear drainage system. The xlHA gel was inserted in office once into the lower lid puncta and canaliculus with a syringe and lacrimal irrigator. Patients were followed for 3 months clinically for efficacy and for adverse events such as infection, swelling, bruising, pain, and Tyndall effect. Patients were excluded if they had a prior history of plugs in their tear ducts or an active eye tear duct infection.

\section{xIHA gel insertion procedure}

The procedure entailed first placing a proparacaine drop onto the surface of the eye. Next a punctal dilator was used to stretch the lower lid puncta. A lacrimal irrigator with saline was introduced into the lower puncta to flush the tear ducts to confirm the patency of the lacrimal outflow system. Approximately $0.2 \mathrm{~mL}$ of xlHA gel (Restylane-L ${ }^{\mathrm{TM}}$, Q Med, Uppsala, Sweden) was introduced into each lower lid canaliculus using a 23 -gauge lacrimal irrigator (Figures 1-3). The average procedure time was 5 minutes.

\section{Results}

Seventy-four patients received the xlHA gel occlusive device in both lower puncta. Sixty-three patients completed the study; 48 were female and 15 were male. The average age

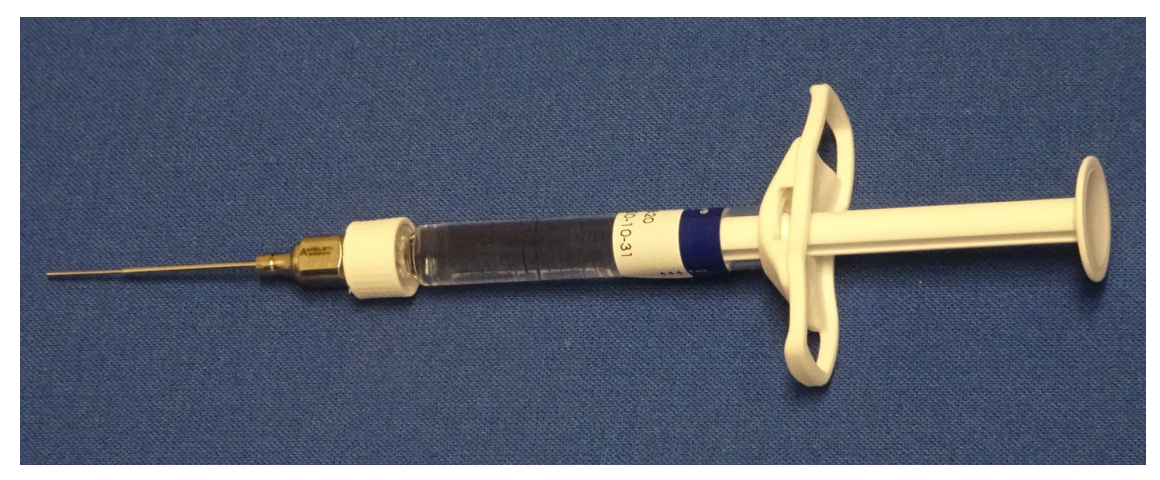

Figure I xIHA gel in syringe attached to a 23-gauge lacrimal irrigator. Abbreviation: xlHA, cross-linked hyaluronic acid. 


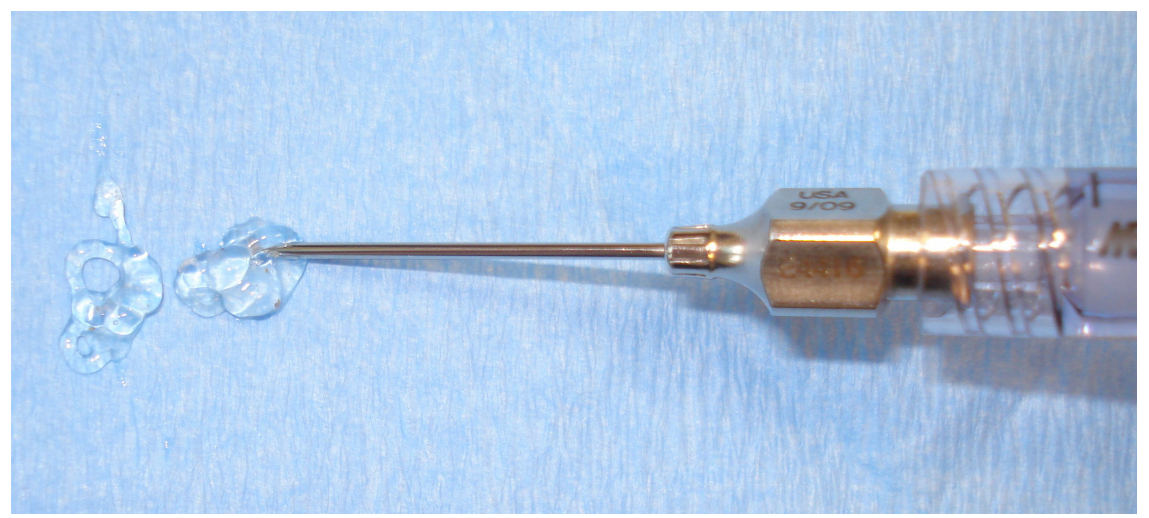

Figure 2 Smooth xlHA gel flow.

Abbreviation: xlHA, cross-linked hyaluronic acid,

was 67 years. All but three were Caucasian; two African American, and one Asian patient. Of the patients who did not complete the study, most missed a follow-up visit and were excluded as per the study criteria.

The xlHA gel was easy to insert and $83 \%$ of patients reported no pain during the insertion procedure. Objective clinical measures such as improvement in corneal staining on SLE confirmed xlHA gel effectiveness. This was supported by several metrics such as Schirmer's test, TBUT, and TMH, which were all statistically significantly improved at 1 and 3 months in this first-in-man study (Figures 4-6).

The 6-month exit questionnaire reported decreased dry eye symptoms such as improved wetness, and $63 \%$ of patients stated that their eyes felt better (Figure 7). Safety was encouraging with $94 \%$ responded no infections. The biggest source of dissatisfaction at the 6-month period was that the xlHA gel did not last long enough. Adverse events were

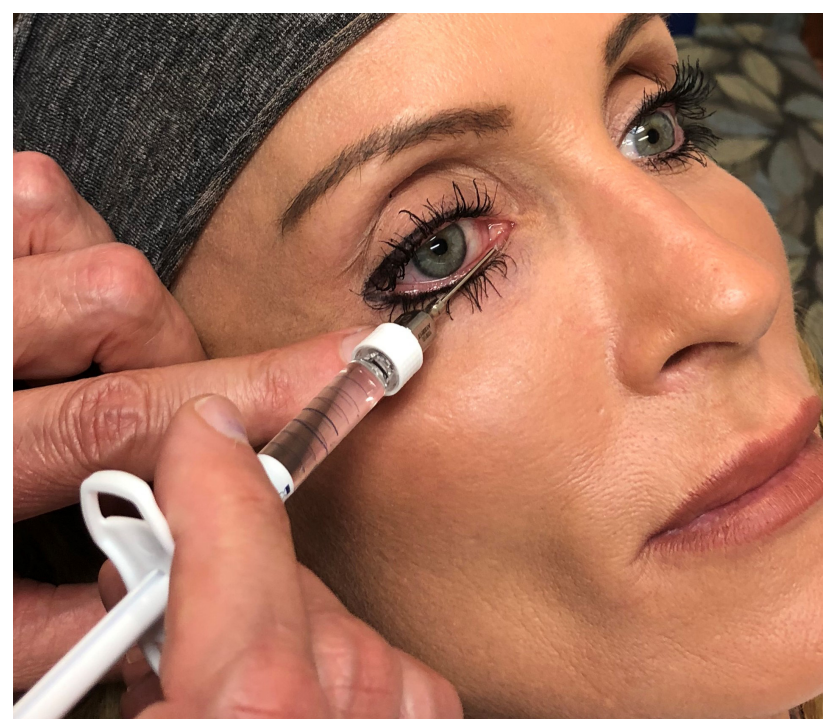

Figure 3 Clinical placement of xlHA gel plug in lower canaliculus with lacrimal irrigator Abbreviation: $x \mathrm{lHA}$, cross-linked hyaluronic acid. rare and included two cases of periocular itching, which was attributed to seasonal allergies and one case of conjunctivitis that occurred at month 2 and resolved and was likely to be an incidental viral infection not related to the gel, as a family member had previously contracted a "pink eye." Importantly, there were no cases of dacryocystitis, canaliculitis, swelling, pain, bruising, or Tyndall effect.

\section{Discussion}

Dry eye symptoms can negatively affect daily functioning and disable people with multiple problems such as decreased vision, burning, irritation, itching, and eye fatigue. An estimated $10 \%-14.4 \%$ of people in the USA suffer from dry eyes. ${ }^{1,2}$ The management of DES includes removal of causative factors, artificial tears, prescription drops, and punctal plugs.

Practitioners commonly rely on adding moisture via drops as a first-line therapy. Manufactured artificial tears cannot replicate nature's own tear composition and therefore are never as beneficial as a person's own tears. The tear film is a complex layering of an outer lipid layer, middle aqueous layer, and inner surface mucin layer, each with an important function. Tear substitutes only attempt to partially replace some of these vital components. Therefore, artificial tears are limited to short-term, palliative, symptomatic relief. Those patients who require additional ocular surface lubrication or are challenged in applying drops often benefit from punctal plugs as a second-line treatment. Plugs block the egress of tears from the ocular surface and increase a patient's own tears to lubricate the eye. This first-in-man study suggests that a new method of treating DES using xlHA gel as a canalicular occlusive device is also possible.

It has been well documented that punctal occlusion is beneficial in both subjective and objective manifestations of dry eye disease with $74 \%-86 \%$ of patients treated with plugs gaining 


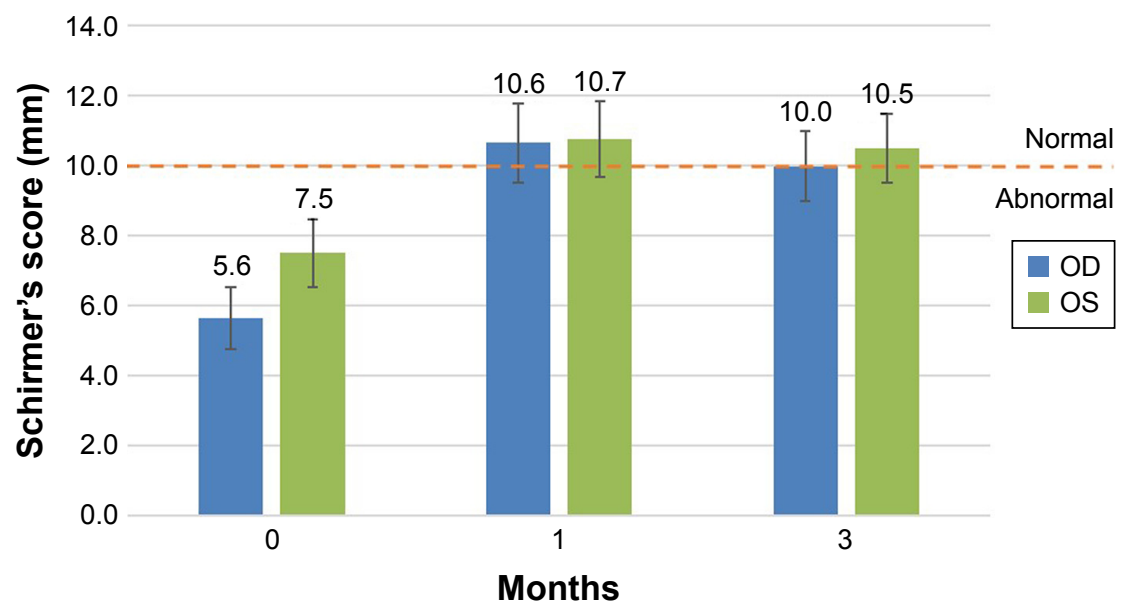

Figure 4 Efficacy: improvement in Schirmer's test.

Notes: An average $3.67 \mathrm{~mm}$ improvement was observed after 3 months from baseline. The error bars represent the standard error of the mean. The pre- and postapplication results are statistically significant $(P<0.05$, paired $t$-test). An increase in tears remaining in the eye validates the functional mechanical occlusion by the gel.

improvement in dry eye symptoms. ${ }^{3}$ Plugs have also been shown to significantly improve dry eye outcome measures such as visual acuity, Schirmer's test, fluorescein corneal staining, tear film quality, TBUT, TMH, tear osmolarity, goblet cell density, and quality of life in patients with aqueous deficiency. ${ }^{4-8}$ The American Academy of Ophthalmology paper on punctal plugs reported a $\geq 50 \%$ improvement of dry eye signs and symptoms that are not responsive to topical treatment. ${ }^{9}$ This included improved ocular surface health, decreased artificial tear use, and improved contact lens tolerance.

Punctal occlusion using traditional solid plugs suffers from drawbacks. The disadvantages of cap plugs include the technical challenges in sizing and placing, the cap head rubbing on the eye, poor retention with rates ranging from $30 \%$ to $90 \%$, spontaneous extrusion, dislodgement, canalicular dissection, infection, and pyogenic granuloma formation requiring surgical removal. ${ }^{3,7,10-14}$ Intracanalicular plugs were popularized partially to circumvent the issue of the cap rubbing on the ocular surface. They are available in many forms such as temporary collagen plugs as a short-term trial to assess efficacy. Intracanalicular plugs can also sometimes be made of harder acrylic material that can erode into the soft lining of the canaliculus. This can lead to an infection and fulminant canaliculitis with bleeding granulation tissue, a bacterial infection, and chronic conjunctivitis necessitating surgical removal. ${ }^{15}$ One survey of American Society of Ophthalmic Plastic and Reconstructive Surgery members reported that $61 \%$ of the respondents encountered complications with intracanalicular plugs such as canaliculitis and that $51 \%$ required surgery to correct the problem. ${ }^{16}$ Although all types of plug can be safe and effective,

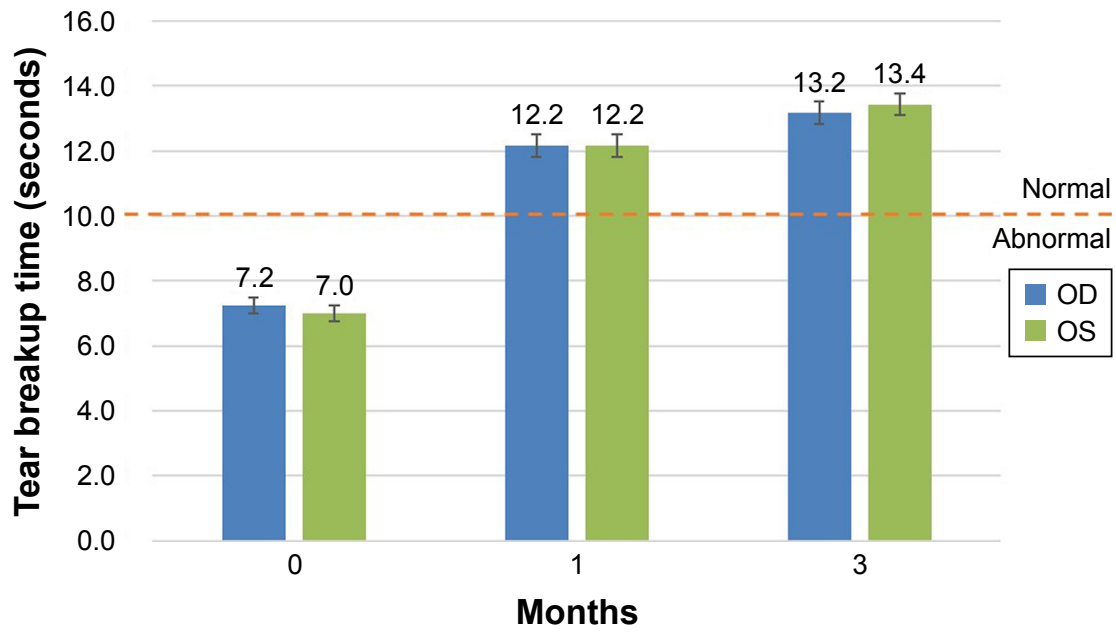

Figure 5 Efficacy: improvement in tear breakup time (TBUT).

Notes: TBUT $<10$ seconds is considered abnormal. This shows an $87 \%$ increase in TBUT over baseline at 3 months. The error bars represent the standard error of the mean. The pre- and postapplication results are statistically significant $(P<0.00 \mathrm{I}$, paired $t$-test). An increase in tear volume validates the functional mechanical occlusion by the gel. 


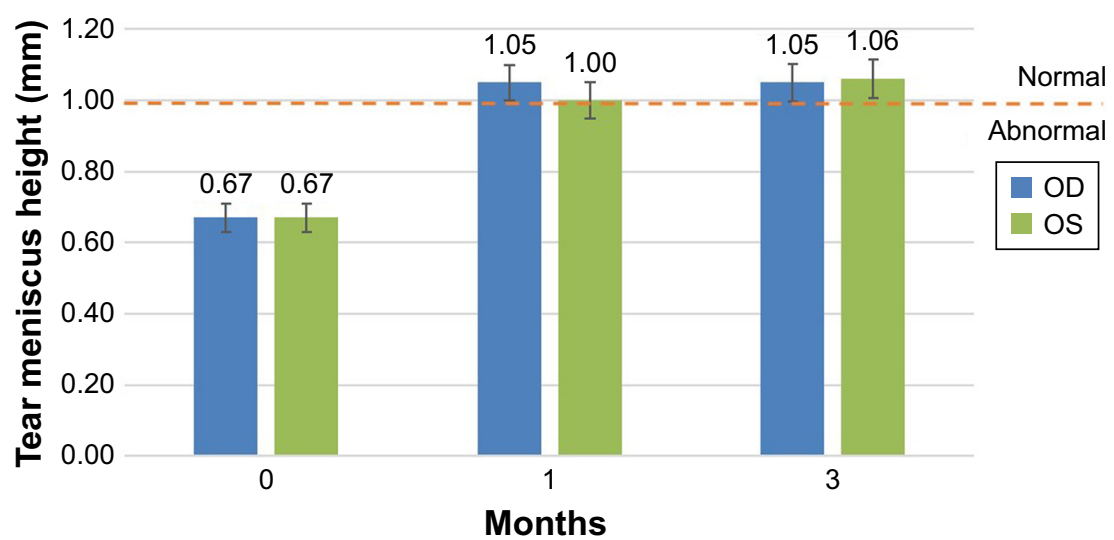

Figure 6 Efficacy: improvement in tear meniscus height (TMH).

Notes: TMH demonstrated a 57\% improvement at 3 months. The error bars represent the standard error of the mean. The pre- and postapplication results are statistically significant $(P<0.001$, paired $t$-test $)$. An increase in tear volume validates the functional mechanical occlusion by the gel.

complications such as infection, allergic reaction, extrusion, and migration can plague current plug designs. ${ }^{17}$

Although a previous study documented that occluding the puncta with hypromellose can reduce DES signs for up to
8 weeks, xlHA gel has properties that make it more desirable for longer term canalicular occlusion..$^{18} \mathrm{xlHA}$ is biocompatible, safe, reversible, has good longevity, repeatable, and composes our vitreous humor. The engineered form of HA does not
A Do eyes feel better?

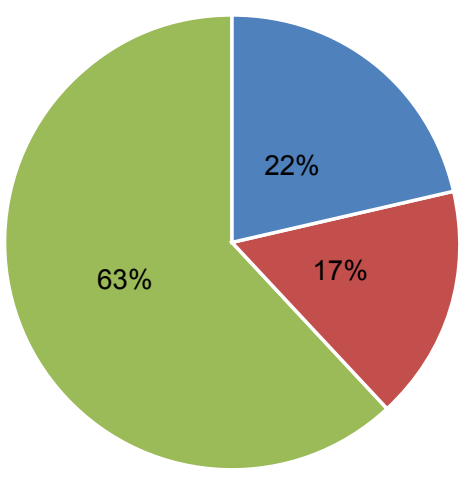

C Any new infections?

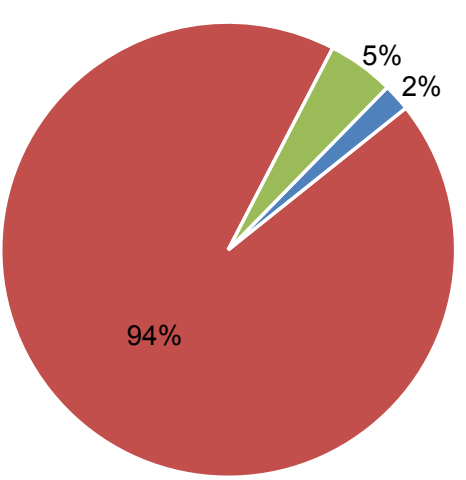

B Do eyes feel wetter?

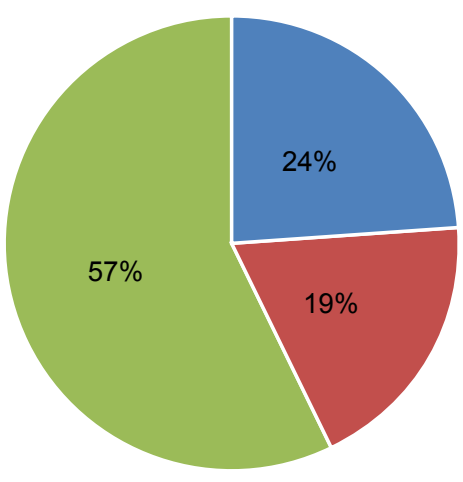

D Any pain?

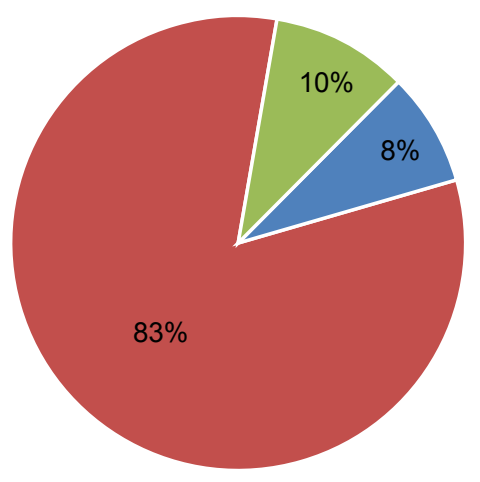

Neutral $\square$ No $\square$ Yes

Figure 7 Six-month exit questionnaire: (A) $63 \%$ of patients reported their eyes felt better, (B) $57 \%$ said they felt wetter, (C) $94 \%$ of patients stated they had no infection, and (D) $83 \%$ said they had no pain. 
require skin testing and it is also reversible by degradation with the enzyme hyaluronidase. ${ }^{19} \mathrm{HA}$ is an osmotic substance well known in medicine with several applications. Among its popular uses, HA is Food and Drug Administration-approved for use in ophthalmic surgery injected intraocularly to maintain eyeball turgor. ${ }^{20} \mathrm{HA}$ is also approved as a dermal filler and for the lubrication of articular joint surfaces. ${ }^{21}$ xlHA has a desirable profile for canalicular occlusion, because it has slower degradation and is longer lasting. ${ }^{22}$ Some xlHA dermal fillers last up to 2 years when injected as a wrinkle filler. ${ }^{23}$

The tear film also relies on HA as a moisturizer and lubricant. As HA is also part of our natural tear film, adding HA topically to tear replacement solutions has been reported to be beneficial in the treatment of dry eyes. ${ }^{24,25}$ Some newer, third-generation artificial tears incorporate HA, as HA's role in maintaining a proper, stable tear film has been well established. ${ }^{26-30}$

To the best of the author's knowledge, this is the first report of the use of xlHA as a canalicular occlusive device in humans. The xlHA gel used in this study (Restylane- $\mathrm{L}^{\mathrm{TM}}$ ) was injected into the lower canaliculus to block the outflow of tears. The xlHA gel swells and molds to the inner surface of the canaliculus. It effectively seals the lacrimal outflow system resulting in increased retention of tears on the ocular surface. The placement of the xlHA gel was achieved painlessly with a lacrimal injector, and most patients had no discomfort during the xlHA gel placement. The office procedure took 5 minutes and is similar to canalicular irrigation.

In this study, a volume of $0.2 \mathrm{~mL}$ was inserted into each lower canaliculus. A report of cyanoacrylate injected into the canaliculus suggested that a volume of only $0.1 \mathrm{~mL}$ was necessary to adequately fill the canaliculus based on experience with cadaver models. ${ }^{31}$ A slightly larger volume was used in this study so as to ensure complete filling of the puncta and canaliculus. Occasionally, the xlHA gel injected into the lower canaliculus would extrude from the upper puncta, indicating that the gel was occupying the entire upper and lower systems. It was felt that the confirmation of an adequate fill was more beneficial than the alternative of under filling of the canalicular system.

Several pertinent findings are encouraging regarding xlHA gel as a canalicular occlusive device. A decrease in fluorescein cornea staining on SLE was observed, and this is consistent with other studies that found punctal occlusion provided reduced fluorescein staining. ${ }^{8}$ Clinical examinations confirmed the benefits of xlHA gel as a canalicular occlusive device at 1 and 3 months with statistical improvement in Schirmer's, TBUT, and TMH.
The limitations of this study are that it was performed at a single site, was single arm, open-label, and without a control group. A $20 \mathrm{mg} / \mathrm{mL}$ commercially available xlHA gel was used as it had a good safety record, but newer HA gels may be more effective. On average, $0.2 \mathrm{~mL}$ of gel was injected, but a smaller amount may be sufficient in some cases.

In summary, the xlHA gel canalicular filler demonstrated a new method to block the lower canaliculus to treat dry eye disease. The results were encouraging and showed both subjective and objective improvements in most patients at 3 months. The xlHA gel has many potential benefits over traditional plugs, including biocompatibility, no sizing, no firm edges, the potential for removal, and a promising safety profile.

\section{Disclosure}

Allergan: Speaker, Consultant, Advisory Board, Principle Investigator FDA Trial. Merz: Consultant, Principle Investigator FDA Trial. Galderma: Speaker, Trainer. Patent Holder: Hyaluronic Acid Gel Plug. Visant Medical: Equity Ownership. The author reports no other conflicts of interest in this work.

\section{References}

1. The epidemiology of dry eye disease: report of the Epidemiology Subcommittee of the International Dry Eye WorkShop (2007). Ocul Surf. 2007;5(2):93-107.

2. Moss SE, Klein R, Klein BE. The prevalence of and risk factors for dry eye syndrome. Arch Ophthalmol. 2000:1181264-1181268.

3. Management and therapy of dry eye disease: report of the Management and Therapy Subcommittee of the International Dry Eye WorkShop (2007). Ocul Surf. 2007;5(2):163-178.

4. Miljanović B, Dana R, Sullivan DA, Schaumberg DA. Impact of dry eye syndrome on vision-related quality of life. Am J Ophthalmol. 2007; 143(3):409-415.

5. Baxter SA, Laibson PR. Punctal plugs in the management of dry eyes. Ocul Surf. 2004;2(4):255-265.

6. Said AM, Farag ME, Abdullah TM. Corneal sensitivity, ocular surface health and tear film stability after punctual therapy of aqueous deficient dry eye. Int J Ophthalmol. 2016;18(9):1598-1607.

7. Brissette AR, Mednick ZD, Schweitzer KD, Bona MD, Baxter SA. Punctal plug retention rates in treatment of dry eye: a randomized, double-masked, controlled clinical trail. Am J Ophthalmol. 2015;160(2): 238-242.

8. Tong L, Beuerman R, Simonyi S, Hollander DA, Stern ME. Effects of Punctal occlusion on clinical signs and symptoms and on tear cytokine levels in patients with dry eye. Ocul Surf. 2016;14(2):233-241.

9. Marcet MM, Shtein RM, Bradley EA, et al. Safety and efficacy of lacrimal drainage system plugs for dry eye syndrome: a Report by the American Academy of Ophthalmology. Ophthalmology. 2015;122(8): $1681-1687$.

10. Tai MC, Cosar CB, Cohen EJ, Rapuano CJ, Laibson PR. The clinical efficacy of silicone punctal plug therapy. Cornea. 2002;21(2):135-139.

11. Kaido M, Ishida R, Dogru M, Tsubota K. Comparison of retention rates and complications of 2 different types of silicon lacrimal punctal plugs in the treatment of dry eye disease. Am J Ophthalmol. 2013;155(4): 648-653. 
12. Parikh NB, Francis JH, Latkany RA. Retention rate of silicone punctal plugs placed by residents in a general clinic setting. Ophthalmic Plast Reconstr Surg. 2010;26(6):400-402.

13. Fayet B, Assouline M, Hanush S, Bernard J, D'Hermies F, Renard G. Silicone punctal plug extrusion resulting from spontaneous dissection of canalicular mucosa: a clinical and histopathologic report. Ophthalmology. 2001;108(2):405-409.

14. Zhang X, Bitar M, Davis RM. Spontaneous canalicular plug erosion after punctal plug placement. Cornea. 2017;36(4):521-522.

15. Hill RH, Norton SW, Bersani TA. Prevalence of canaliculitis requiring removal of SmartPlugs. Ophthalmic Plast Reconstr Surg. 2009;25(6): 437-439.

16. Lee J, Flanagan JC. Complications associated with silicone intracanalicular plugs. Ophthalmic Plast Reconstr Surg. 2001;17(6):465-469.

17. Jehangir N, Bever G, Mahmood SM, Moshirfar M. Comprehensive review of the literature on existing punctal plugs for the management of dry eye disease. J Ophthalmol. 2016;2016:1-22.

18. Capita L, Chalita MR, dos Santos-Neto LL. Prospective evaluation of hypromellose $2 \%$ for punctal occlusion in patients with dry eye. Cornea. 2015;34(2):188-192.

19. Cavallini M, Gazzola R, Metalla M, Vaienti L. The role of hyaluronidase in the treatment of complications from hyaluronic acid dermal fillers. Aesthet Surg J. 2013;33(8):1167-1174.

20. Pape LG, Balazs EA. The use of sodium hyaluronate (Healon) in human anterior segment surgery. Ophthalmology. 1980;87(7):699-705.

21. Iwata H. Pharmacologic and clinical aspects of intraarticular injection of hyaluronate. Clin Orthop Relat Res. 1993;289(289):285-291.

22. Tomihata K, Ikada Y. Preparation of cross-linked hyaluronic acid films of low water content. Biomaterials. 1997;18(3):189-195.
23. Glaser DA, Kenkel JM, Paradkar-Mitragotri D, Murphy DK, Romagnano L, Drinkwater A. Duration of effect by injection volume and facial subregion for a volumizing hyaluronic acid filler in treating midface volume deficit. Dermatol Surg. 2015;41(8):942-949.

24. Polack FM, McNiece MT. The treatment of dry eyes with $\mathrm{Na}$ hyaluronate (Healon $\left.{ }^{\circledR}\right)$ Cornea. 1982;1(2):1333.

25. Deluise VP, Peterson WS. The use of topical Healon tears in the management of refractory dry-eye syndrome. Ann Ophthalmol. 1984;16(9): 823-824.

26. Nelson JD, Ferris RL. Sodium hyaluronate and polyvinyl alcohol artificial tear preparations a comparison in patients with keratoconjunctivitis sicca. Arch Ophthalmol. 1989;106:484-487.

27. Guillaumie F, Furrer P, Felt-Baeyens O, et al. Comparative studies of various hyaluronic acids produced by microbial fermentation for potential topical ophthalmic applications. J Biomed Mater Res A. 2010; 92(4):1421-1430.

28. Jones L, Downie LE, Korb D, et al. TFOS DEWS II Management and Therapy. Report Ocul Surf. 2017;15(3):575-628.

29. Simmons PA, Vehige JG. Investigating the potential benefits of a new artificial tear formulation combining two polymers. Clin Ophthalmol. 2017;11:1637-1642.

30. Pinto-Fraga J, López-de La Rosa A, Blázquez Arauzo F, Urbano Rodríguez R, González-García MJ. Efficacy and safety of $0.2 \%$ hyaluronic acid in the management of dry eye disease. Eye Contact Lens. 2017;43(1):57-63.

31. Diamond JP, Morgan JE, Virjee J, Easty DL. Cannalicular occlusion with cyanoacrylate adhesive: a new treatment for the dry eye. Eye. 1995;9(Pt 1):126-129.
Clinical Ophthalmology

\section{Publish your work in this journal}

Clinical Ophthalmology is an international, peer-reviewed journa covering all subspecialties within ophthalmology. Key topics include: Optometry; Visual science; Pharmacology and drug therapy in eye diseases; Basic Sciences; Primary and Secondary eye care; Patien Safety and Quality of Care Improvements. This journal is indexed on

Submit your manuscript here: http://www.dovepress.com/clinical-ophthalmology-journal

\section{Dovepress}

PubMed Central and CAS, and is the official journal of The Society of Clinical Ophthalmology (SCO). The manuscript management system is completely online and includes a very quick and fair peer-review system, which is all easy to use. Visit http://www.dovepress.com/ testimonials.php to read real quotes from published authors. 